\title{
ASSESSMENT OF URBAN RESILIENCY CONCERNING DISASTER RISK: A REVIEW ON MULTI-DIMENSIONAL APPROACHES
}

\author{
Tusar Kanti Roy, Sharmin Siddika, Mizbah Ahmed Sresto* \\ Department of Urban and Regional Planning, Khulna University of Engineering \& Technology, Bangladesh
}

Received: 08 July 2021

Accepted: 28 December 2021

\begin{abstract}
There have been a number of new research published with different methodologies and frameworks in recent years, aimed at improving city resilience to a variety of man-made and natural calamities. As climate change progresses, resilience will become a more important topic in scientific and policy circles that influence future urban development. This review article first provides the definition of resilience. Then it represents some of the adopted methodologies in an extensive way. Approaches including Baseline Resilience Indicators for Communities (BRIC), Climate Disaster Resilience Index (CDRI), Disaster resilience index based on Analytic Hierarchy Process (AHP), Composite indicator based approach, Hyogo Framework and so on. This section discusses about urban resiliency assessments to mitigate vulnerability, offer a set of principles and indicators for creating an urban resilience assessment tool. Findings of this study not only address a variety of qualitative and quantitative aspects of urban resilience but also describes about different indicators such as environmental resources, socio-economic and built environment, infrastructure, governance and institutional indicators.
\end{abstract}

Keywords:Climate change; Disaster risk; Resilience; Urban resiliency; Vulnerability.

\section{INTRODUCTION}

Climate resilient cities seem to be a main goal of disaster management institutions around the world in recent years, as resilient communities are more likely to incur less losses and recover more rapidly when faced with a disaster (Scherzer et al. 2019). Resilience is defined as a system's ability to overcome changes produced by one or more disrupting components and return to its original condition or normal functioning (Rickson, 2020). It can be characterized as a community's or city's ability to plan and prepare, absorb and withstand, recuperate from, and efficiently adapt to real or possible adverse occurrences in an effective and organized manner, which includes the preservation and strengthening of essential functions and structures (Scherzer et al. 2019; Cutter et al. 2014). Resilience is often regarded as a positive and desirable characteristic. When confronted with a hazardous event, a resilient community will incur lesser loss and recover more rapidly. Climate resilience is the ability of a socio-economic and ecological system to adapt, reorganize, and develop into more desirable configurations that improve sustainability and prepare it for future climate change impacts (Folke 2006; Nelson, Adger \& Brown, 2007).

Urban areas will be subjected to a variety of stressors as a result of climate change. Severe storms, rising sea levels, temperature changes, environmental degradation, and unfavorable climatic phenomena are expected to be direct impacts, while some will be indirect impacts that resonate through the systems which urban regions rely on, such as energy, transportation, and communications (P. Robinson \& Gore, 2015, Tylor \& Monech, 2012). Changing climate and urban resiliency literature is increasingly multidisciplinary and extensive (Leichenko, 2011). It is one of the many dangers that cities face. Higher temperatures, rising sea levels, more violent thunderstorms, drought, and heat waves are all expected consequences of climate change (Jabareen, 2013). Also it poses a threat to urban infrastructure in particular. Cities, especially those along the shore, are particularly vulnerable to increasing rise of sea level, tropical storm and storm surge. Due to the increasing level of energy consumption and extraction of raw materials, cities are also major contributors to climate change and emission of carbon (OECD, 2010).

Climate change is affecting people all over the world, posing a threat to basic human needs such as access to clean water, food, health, and land use, as well as the natural habitat (Mishra, 2017). Some anthropogenic activities, such as urbanization, have been recognized as primary sources of continuous climate change. Climate change's direct and indirect consequences on low and middle income people can now be seen in countries that play the least influence in climate change and global warming. The effects of growing urbanization and *Corresponding Author:sresto1617056@stud.kuet.ac.bd 
environmental degradation are dangerously convergent. On the other hand, cities are substantial contributors to climate change. Despite occupying less than $2 \%$ of the earth's surface, cities use up to $78 \%$ of the world's energy and produces more than $60 \%$ of all carbon dioxide and significant amount of other greenhouse gas emissions, largely through energy generation, vehicles, industry, and biomass use (Klein et al. 2003).

Cities all across the world have come to appreciate the importance of identifying and overcoming urban climate vulnerabilities. This study demonstrates the diverse processes of adopting resilience in each city, as well as the variances in each research's methodology. Existing governance mechanisms, industrial mix, population and demography, as well as the expertise of partnerships and comfort levels, are all contextual considerations in any city.

The concept of urban resilience is dynamic and suggests numerous pathway to resilience for example resolution, transition, and conversion. It emphasizes the relevance of time scale and prefers broad adaptability over specialized adaptability. As a sophisticated and adaptive system, the urban resilience system is made up of socioeconomic, socio- ecological, and technical complexity that are spread across several geographic scales. As resilience is outlined as an anticipated state it should be conveyed amid the people who sanction it empirically. Resilience breaks down the severity of climate change into smaller, more manageable tasks, such as lowering increased flood risk from rising sea levels or strengthening agriculture sector for longer droughts as a result of rising temperatures. For every individual community the effect of resilience is different based on the impact of climate change on that community. Without building up a resistance a city is always vulnerable to natural and manmade havocs.

This paper focuses on the theoretical foundations of this concept. The technique for conducting the literature review is described in Section 2, as well as the classification of prior conceptions of urban resilience. The third section examines the influential literature in the topic and builds on the six theoretical tensions. Section 4 deconstructs the components of this new definition and explains why they were chosen. The study finishes with a consideration of how the phrase "urban resilience" might be used as a boundary object, allowing for the essential collaboration to consider resilience for whom, what, when, where, and why.

\section{THEORETICAL FRAMEWORK}

Different review process such as narrative, scoping review, systematic review and other review approaches were employed earlier (Davis et al. 2009; Rumrill et al. 2010). Following previous review processes, scholarly literature are included in this narrative review process. To determine the eligibility of a scholarly work, this study used a number of criteria. To begin, only peer-reviewed urban and regional planning journals with articles published exclusively in English were considered. A three-stage approach was used for this purpose. First of all, website of SCImago was checked because it contains thousands of journals from different fields and among them more than 40 journals form Urban Studies category were chosen and after that 10 most relevant journals were chosen by observing the articles, scope of the journals, SJR and H index. The title, abstract, and keywords of all articles published in these 10 journals were reviewed in the first stage. It is because key terms like "climate action" may have originally referred to mitigation, but now they refer to both mitigation and adaptation that creates a pathway to resilience. However, another 5 journals were selected based on the scope of the journal from urban planning and design, resilience, and climate change adoption literature. Finally, a few more urban planning, development and design related research articles, reports, review articles were considered because they have the potential to connect urban planning and resilience.

More specifically, the academic sources used to gather information are drawn from the following areas of study: adaptation to climate change, resilience to climate change, international planning and development, and disaster risk assessment. During the assessment process, around 50 scholarly sources were considered from the selected journals list. For performing assessment of all the research article firstly definition of urban resiliency given by different researchers was evaluated, secondly disaster risk redetection approach, frameworks, qualitative and quantitative approaches were evaluated and thirdly the results and outcomes of each type of approaches were in this review article. 


\section{URBAN RESILIENCE: DEFINITIONS FOR BETTER UNDERSTANDING}

Table 1: Definition of Urban resilience

\begin{tabular}{|c|c|}
\hline Author & Definition \\
\hline $\begin{array}{l}\text { (Alwang, Siegel, \& } \quad \& \\
\text { Jorgensen, 2001) }\end{array}$ & $\begin{array}{l}\text { The capability to withstand downward forces and emerge from a shock is referred to } \\
\text { as resilience. Property that permits a system to absorb, use, and even gain from } \\
\text { change, according to ecological literature. Where resilience is great, a substantial } \\
\text { disturbance is required to overcome the system's constraints to vast improvement and } \\
\text { allow it to be rapidly changed into a different state. }\end{array}$ \\
\hline $\begin{array}{l}\text { (Walker, Anderies, } \\
\text { Kinnzig, \& Ryan, 2006) }\end{array}$ & $\begin{array}{l}\text { Resilience is a system's ability to stay in a single component while maintaining its } \\
\text { feedback mechanisms and operations. It also refers to the system's ability to } \\
\text { reorganize after a disturbance-driven change. }\end{array}$ \\
\hline (Gregg et al. 2006) & $\begin{array}{l}\text { Resilience can be defined as a measure of people's and society' adapt to changing } \\
\text { circumstances and maximize on new opportunities by improving strategies. }\end{array}$ \\
\hline (Godschalk, 2003) & $\begin{array}{l}\text { A long-term network of sustainable physical systems and human groups capable of } \\
\text { dealing with extreme catastrophes; both must be capable of surviving and operate } \\
\text { under great stress during, before and after disaster. }\end{array}$ \\
\hline (Pfefferbaum & The ability of people in the community to take meaningful, intentional, and collective \\
\hline $\begin{array}{l}\text { Pfefferbaum, \& RL., } \\
\text { 2011) }\end{array}$ & $\begin{array}{l}\text { action to mitigate the effects of a crisis, including the ability to understand the } \\
\text { environment, act, and moving on. }\end{array}$ \\
\hline (Holling, 1973) & $\begin{array}{l}\text { Resilience is a measurement of a system's capability to withstand change and disorder } \\
\text { while maintaining the same connections between population or state variables. }\end{array}$ \\
\hline (Folke et al. 2010). & $\begin{array}{l}\text { Resilience is a term that refers to the capacity of complex social and ecological } \\
\text { system to evolve, adapt, and, most crucially, alter in response to disruptions and } \\
\text { constraints. }\end{array}$ \\
\hline Ahmed, & The creation of material, physical, socio-political, socio-cultural, and psychological \\
\hline $\begin{array}{l}\text { Niekerk, \& Bulbulia, } \\
\text { 2004) }\end{array}$ & ensure citizens' safety and mitigate adversities. \\
\hline (Klein et al.2004) & $\begin{array}{l}\text { The aptitude of a stressed system to recovery and back to its normal condition; more } \\
\text { specifically, (i) the amount of disruption a system can take while remaining in the } \\
\text { same condition or domain of interest, and (ii) the extent to which the system may } \\
\text { self-organize. }\end{array}$ \\
\hline
\end{tabular}

\section{METHODOLOGICAL APPROACH FOR URBAN RESILIENCY INDEXING}

\subsection{Previously Adopted Methodologies at a Glance}

For this study authors have reviewed several methodologies applied to determine urban resiliency in context of different cities.

Table 2: Methodologies reviewed by the authors

\begin{tabular}{ll}
\hline \multicolumn{1}{c}{ Methodology Type } & \multicolumn{1}{c}{ Author } \\
\hline $\begin{array}{l}\text { 1. Baseline Resilience Indicators for Communities } \\
\text { (BRIC) }\end{array}$ & (Scherzer et al. 2019) \\
2. Climate Disaster Resilience Index (CDRI) & ( Joerin et al. 2014) \\
3. Nations Office for Disaster Reduction & ( Orencio \& Fujii, 2013; Alshehri et al. 2015) \\
4. Analytic Hierarchy Process (AHP). & (Nardo et al. 2005) \\
5. Composite Indicator Based Approach & (Nations, 2015; UNISDR, 20005) \\
6. Hyogo Framework & \\
\hline
\end{tabular}




\subsection{Description of Previously Adopted Methodologies}

\subsubsection{Baseline Resilience Indicators for Communities (BRIC): A Community Resilience Index}

The BRIC method is constructed using a straightforward recursive add and average method. The variables are accumulated in their corresponding resilience sub-domains and aggregated to establish the sub-indices after minimum-maximum transformation. To construct the final community resilience index, the sub-indices scores are min-max converted again and then added. In the original BRIC, all variables within subdomain and all subindices were equally weighted.

$$
\begin{aligned}
& \text { Minimum-maximum transformation, } x^{\prime}=\frac{x-x_{\max }}{x_{\max }-x_{\min }} \\
& \text { Sub-index score, } \mathrm{SUB}=\left(\frac{1}{N} \sum_{i=1}^{N} x^{\prime}\right) \\
& \text { BRIC Score, } \mathrm{BRIC}=\mathrm{SocR}_{\mathrm{m}}+\text { EconR }_{\mathrm{m}}+\mathrm{InstR}_{\mathrm{m}}+\mathrm{ComC}_{\mathrm{m}}+\mathrm{InfR}_{\mathrm{m}}+\text { EnvR }_{\mathrm{m}}
\end{aligned}
$$

To create a range of 0 to 1 using a variable or sub-index, equation (1) is required. The significance of any observation for a specific variable is represented by $x$, and the minimum and maximum values of that variable are denoted by $\mathrm{x}_{\min }$ and $\mathrm{x}_{\max }$, respectively. $x^{\prime}$ is the observation's minimum-maximum transformed score. The computation of the sub-indices (SUB) is defined by equation (2), where all variables $x^{\prime}$ belongs to a particular sub-domain are added together and divided by the total set of variables in that sub-domain, N. The final community resilience index (BRIC) is calculated using equation (3). The sum of the six sub-index scores is calculated as: social (SocR), economic (EconR), institutional (InstR), community resources (ComC), infrastructure and housing ( $\mathrm{InfR}$ ), and environmental (EnvR). The subscript ' $\mathrm{m}$ ' denotes that the sub-index scores have already been min-max transformed before being added.

The BRIC (Baseline Resilience Indicators for Communities) is applied in Norway. According to the data collected from 2014, Norway has 428 municipalities divided into 19 counties and five regions (Scherzer et al. 2019). The values of the sub-index and the overall resiliency index are visually presented in the research of Scherzer et al. (2019). With a standard deviation of 0.45 , the average total resiliency score for all municipalities is 2.48. The highest resilient score is 3.94 , while the least resilient value is 0.92 . The resilience scores are represented in the maps using standard deviation categorization.

There are high levels of comparative resiliency when a municipality has a standard deviation greater than 1.5 beyond the mean (scores $>3.17$ ) (Scherzer et al. 2019). There are several instances where larger urban areas coincide with this resiliency score. Resilience is strong in several prominent Norwegian cities, including Oslo, Bergen, Stavanger, Trondheim, and Drammen. Furthermore, 5 metropolises in Oslo's larger metropolitan area, as well as two metropolises in Stavanger's municipal area, comes into this group. Troms and Bod, the North's two major cities, are similarly robust. Six communities with fewer than 2,000 residents, on the other hand, fall into the same group.

A score between 2.71 to 3.17 is considered as moderately high score follows a zigzag pattern from Central Norway (northern Trøndelag) to Eastern Norway (Østlandet), Western Norway (Vestlandet) and Southern Norway (Sørlandet). Municipalities encompassing the Oslo and Stavanger metro areas, as well as a few dispersed along the coast, mainly coinciding with larger towns, have rather high rankings.

While the northern region, which includes the municipality on the Russian border, has only three relatively high scores, it has the highest number of low resiliency ratings (less than 2.26). Northern Norway's average score is 2.04 with a mean difference of 0.43 . The average score for the remaining four southern regions is 2.60 , with a mean difference of 0.38 .

\subsubsection{The Adoption of a Climate Disaster Resilience Index (CDRI)}

Economic, institutional, natural, physical, and social elements comprise the CDRI framework. Five dimensions, 25 parameters (five for each dimension), and 125 variables (five for each parameter, 25 for each dimension) are 
used to cover major components of a community's resilience to climate-related disasters within this area (Figure $1)$.

\begin{tabular}{|c|c|c|}
\hline & Electricity & Access, availability, supply capacity, alternative capacity \\
\hline & Water & Access, availability, supply capacity, alternative capacity \\
\hline \multirow[t]{5}{*}{ Physical } & Sanitation, solid waste & Access to sanitation, collection of waste, recycle, treatment \\
\hline & Accessibility of roads & $\begin{array}{l}\text { Percentage of land transportation network, paved roads, roadside covered drains, } \\
\text { accessibility during floods }\end{array}$ \\
\hline & Housing and land use & Building code, ownership, population living near industries, non-permit structures \\
\hline & Population & Population growth, density, informal settlers, density at day and night \\
\hline & Health & $\begin{array}{l}\text { Population suffering diseases, water borne diseases, access to primary health care, } \\
\text { capacity of healthcare facilities during disaster }\end{array}$ \\
\hline \multirow[t]{5}{*}{ Social } & Education and awareness & Literacy rate, population awareness of disasters, access to internet \\
\hline & Social capital & $\begin{array}{l}\text { Population participating in community activities, level of segregation, level of } \\
\text { democracv. acceptance of community }\end{array}$ \\
\hline & $\begin{array}{l}\text { Community preparedness } \\
\text { during disaster }\end{array}$ & $\begin{array}{l}\text { Preparedness, shelter, support from non-govt. organization, population } \\
\text { evacuation, population participating in relief work }\end{array}$ \\
\hline & Income & $\begin{array}{c}\text { Population below poverty line, income source number per household, informal } \\
\text { sector income }\end{array}$ \\
\hline & Employment & $\begin{array}{c}\text { Percentage of labor unemployed, percentage of child labor, percentage of youth } \\
\text { unemployed, percentage of women employment }\end{array}$ \\
\hline \multirow[t]{5}{*}{ Economic } & Household assets & Basic furniture, electric gadgets, motorized and non-motorized vehicles. \\
\hline & Finance and savings & $\begin{array}{l}\text { Credit facility, accessibility of credit among poor, saving practices, property } \\
\text { insurances. }\end{array}$ \\
\hline & Budget and subsidy & $\begin{array}{c}\text { Budget for disaster risk reduction, alternative livelihood, post disaster health, } \\
\text { budget for disaster risk reduction }\end{array}$ \\
\hline & $\begin{array}{l}\text { Disaster risk reduction and } \\
\text { climate change adaptation }\end{array}$ & $\begin{array}{l}\text { Zone development plan, manpower, technical capacity, community participation } \\
\text { extent, implementing disaster management plan. }\end{array}$ \\
\hline & $\begin{array}{l}\text { Effectiveness of zone's crisis } \\
\text { management framework }\end{array}$ & $\begin{array}{l}\text { Existence and effectiveness of emergency team, availability of evacuation } \\
\text { centers, leadership, efficiency of trained emergency workers }\end{array}$ \\
\hline \multirow{4}{*}{ Institutional } & $\begin{array}{l}\text { Knowledge dissemination and } \\
\text { management }\end{array}$ & $\begin{array}{c}\text { Effectiveness of learning from previous events, disaster training program, } \\
\text { disaster awareness program, disaster education. }\end{array}$ \\
\hline & Good governance & $\begin{array}{l}\text { Effectiveness of early warning system, existence of disaster drills, accurate } \\
\text { emergency information, capability of zone body to lead recovery process. }\end{array}$ \\
\hline & Intensity of natural hazards & Flood, cyclone, heat wave, drought, salinity, water crisis. \\
\hline & Freavency of natural hazards & Flood, cyclone, heat wave, drought, salinity, water crisis. \\
\hline \multirow[t]{2}{*}{ Natural } & & Quality of city's biodiversity, soil, air, water bodies, salinity. \\
\hline & Land use in natural terms & $\begin{array}{c}\text { Area vulnerable to climate related hazards, urban morphology, settlements of } \\
\text { hazardous ground, amount of green space. }\end{array}$ \\
\hline
\end{tabular}

Figure 1: Framework describing CDRI parameters and variables

Each variable $(\mathrm{x} 1, \mathrm{x} 2, \mathrm{x} 3, \mathrm{x} 4, \mathrm{x} 5)$ provides five alternative options ranging from not unavailable or badly available (score of ' 1 ') to the best (score of ' 5 ') in terms of availability. A weighting scheme also demands that variables within a parameter, which consists of five variables, be graded (w1, w2, w3, w4, w5) according to their importance (low importance (' 1 '), high importance (' 5 ') in determining the final score of a parameter or dimension. This simple standardized questionnaire, which uses uniform numbers ranging from ' 1 ' to ' 5 ' for each parameter and variable, allows for the straightforward use of a weighted mean to measure CDRI scores for each variable, factor, and dimension in a consistent and harmonized manner (equation 4).

$\sum w i x i / \sum w i=w 1 \times 1+w 2 \times 2+w 3 \times 3+w 4 x 4+w 5 \times 5 / w 1+w 2+w 3+w 4+w 5$ 
The CDRI assessment yielded the following results: higher scores indicate greater resilience (the maximum score is ' 5 '), whereas lower scores indicate decreased resilience (the minimum score is ' 1 ').

Greater scores (maximum of 5) indicate greater resilience, whereas lower values (minimum of 1) indicate lower resilience. The northern sections of Chennai more specifically zone I, II and III have lesser resiliency than the southern, central, and western parts of the city, as shown in the research of Joerin, Shaw, Takeuchi, \& Krishnamurthy (2014). This is owing to these areas' limited economic and natural resilience. Due to the extreme substantial number of urban poor and high income inequality, economic resilience is poorer, resulting in cumulative consequences. Other economic considerations, such as administration ability of zones and its citizen to provide financing for disaster-prevention measures, become constrained. Heavy businesses, such as the port in zone II, a huge garbage assortment facility in zone I, a huge coal based power plant, rely heavily on the soil in the northern sections which is zone I, II, and III. Due to the degradation of ecosystem services and thus reduced capacity to handle additional stresses or shocks, these areas have lower natural resilience. Despite the fact that one of the city's major transportation circuits runs through it, Chennai's central (zone VII) has the highest inherent resilience of all zones. Higher economic resilience scores are connected with recent development efforts in the southern and western portions of the city, as there is relatively little new development in the northern sections of Chennai, aside from the bustling port (zone II) ( Joerin, Shaw, Takeuchi, \& Krishnamurthy, 2014).

The findings of the CDRI assessment are summarized in the next section:

On contrary to the social dimension, in which certain locations do much better than others, the CDRI's economic and environmental aspects seems to correlate to the current situation. This could be owing to the city's usually mixed land-use character or it could be due to the CDRI tool's concentration on the zone level rather than the household level (CMDA, 2008). There is no clearly recognizable single business district, and there is no predominance of urban poor communities in just one zone (a conclusion derived from observations). However, the northern districts are made up of more diverse groups (different castes and religions). Furthermore, villages in this area gain less from the city's economic expansion (particularly in the south and west), as seen by their lower socioeconomic potential. As a result of their economic, natural, and social limitations, the northern regions of the city are less resilient than other parts of the metropolis (lower resilience) (CMDA, 2008).

When the CDRI results are compared, the economic, natural, and social resilience aspects show more difference among the zones with the highest and lowest scores, but the institutional and physical aspects show less variation. The modest degree of variance in the institutional dimension is due to the zones' administrative goal of undertaking civic activities at a lower institutional level than the entire city. As a result, it is unsurprising that all zones have identical institutional resilience scores. The little amount of diversity in the physical dimension, on the other hand, is due to the city's centralized and equitable distribution of electricity and water. Thus, physical factors such as road accessibility, solid waste disposal, and land use in relation to housing determine whether a zone will perform better or worse during a climate-related disaster.

\subsubsection{Simpsons Community Resilience Index}

We utilize the UNISDR concept of resilience in this assessment, which defines resilience as the ability to tolerate, absorb, and accommodate the impact of hazard in an effective manner. As a result, the proposed resilience index is based on Simpson's concept of community resilience as the ratio of readiness to vulnerability in a community.

The study's goal is to provide a framework for analyzing an area's resilience to natural disasters, and to put it into practice by measuring the resilience of Cilacap region and Padang city in Indonesia. Having a clear knowledge about the concept of resilience to natural disasters allows for recommendations on public policy in disaster management that can increase the area's resilience to natural disasters, reducing the disaster's impact on the community and business, and shortening the recovery period.

The preparedness score (PI) is the sum of the weighted scores of all dimensions score (PD), while the dimension score is the sum of the weighted scores of all sub-dimensions (PS). Finally, the average score of the subindicators dimensions is determined. Here, $\mathrm{N}$ stands for number of dimensions, $\mathrm{i}$ is indicated as preparedness 
dimension, $\mathrm{j}$ is indicated as sub-dimension and $\mathrm{k}$ is the indicator. The process of PI, PD and PS calculation is given below- (equation 5, $6 \& 7$ ).

$$
\begin{aligned}
& P I=\sum_{i=1}^{i=N P} w_{i} P D_{i} \\
& P D i=\sum_{j=1}^{j=M P_{i}} u_{j i} P S_{j i} \\
& P S_{i j}=\frac{\sum_{k=1}^{k=L P j} P C_{i j k}}{L P_{j}}
\end{aligned}
$$

As previously noted, the area's preparedness and vulnerability influence its resilience. The preparedness score (PI) is the sum of the weighted scores of all dimensions (PD), whereas the dimension score is the sum of the weighted scores of all sub-dimensions' scores (PS). Finally, the sub-indicators dimensions' average score is calculated. The vulnerability score (VI), like the preparation score, is determined in the same way (equation 8,9 $\& 10$ ). Here, $\mathrm{N}$ stands for number of vulnerability dimensions, i is indicated as vulnerability dimension, $\mathrm{j}$ is indicated as sub-dimension and $\mathrm{k}$ is the indicator. Besides $\mathrm{x}$ and $\mathrm{y}$ indicates weight.

$$
\begin{aligned}
& V I=\sum_{i=1}^{i=N V} y_{i} V D_{i} \\
& V D i=\sum_{j=1}^{j=M V_{i}} x_{j i} V S_{j i} \\
& V S_{i j}=\frac{\sum_{k=1}^{k=L V j} V C_{i j k}}{L V_{j}}
\end{aligned}
$$

The resilience score (RI) is then calculated as (equation 11) -

$$
R I=\frac{P I}{V I}
$$

If the value is less than 1, the region is not resilient to natural disasters because its ability to withstand the disaster is less than its vulnerability. If the value is 1 , it indicates that the region has only enough potential to resolve its vulnerability. If the value is greater than one, the region is more resilient to natural disasters because it has the potential to resolve its weakness.

The vulnerability scores of Calicap and Padang areas are close to 0.4. For Cilacap, this is due to the high weights of social and hazard dimensions ( 0.216 and 0.206 , respectively), and their relatively high vulnerability scores ( 0.5482 and 0.7473 , respectively). Cilacap has been hit by 5 of the 7 categories of natural disasters, and the number of catastrophes in this area over the previous 15 years has been rather high, but more crucially, it was hit by an earthquake in 2006, which resulted in substantial human and property loss. As a result, natural disasters are common in the area. Cilacap's demographic profile make it more sensitive to disasters in terms of social vulnerability. Because there is an increasing tendency of population density and poverty. Padang's vulnerability score is 0.940 for hazard and 0.6937 for economic factors respectively (Kusumastuti et al., 2014). Padang has had 6 out of 7 categories of natural catastrophes, as well as a high number of disaster incidents, in the last 15 years. It was struck by an earthquake in 2009, which resulted in substantial human and property losses, making the area extremely vulnerable to natural disasters. In terms of community vulnerability, Cilacap has a score of 0.00 , while Padang has a score of 0.0848 , indicating that there have been a few social disputes in Padang during the previous 15 years comparing to other places in Indonesia. This state should be maintained because the social dimension is the primary determinant of the area's vulnerability (Kusumastuti et al. 2014).

Cilacap and Padang have vulnerability scores of 0.4393 and 0.6937 , respectively, in terms of economic vulnerability. This is mostly due to a high vulnerability score in wealth generation as a result of higher expenditure per capita and a higher percentage of expenditure for everyday requirements as compared to other locations in Indonesia. Cilacap has a substantially higher institutional vulnerability score than Padang, which is due to the vast number of villages that must be administered by the local administration. It means that more effort should be put into coordinating catastrophe mitigation and response actions with village chiefs and community leaders. Finally, Cilacap has a lower infrastructure vulnerability score than Padang, which is due to the low percentage of land used for residential purposes. It implies that evacuating residents in the case of a calamity will be very simple (Kusumastuti et al. 2014).Cilacap regency's natural disaster resilience score is 1.7006, which is slightly lower than Padang's (1.8280), showing that both locations have the potential to overcome disaster vulnerability. However, by improving readiness and/or reducing vulnerability, both sectors' resilience can be strengthened even more. As stated in the preceding subsections, community has the highest 
weight among the preparedness dimensions, and current conditions show that the community's understanding of disaster risk and mitigation is still relatively low.

\subsubsection{Disaster-resilience Index based on Analytic Hierarchy Process}

Saaty (1980) established the Analytic Hierarchy Process (AHP), which is a strong and flexible framework for solving complicated decision-making problems (Boutkhoum et al. 2014). It's a strategy for determining the relative importance of criteria using pairwise comparisons where a rating 1 to 9 is given for performing the evaluation (UN, 2009). To overcome the limitations of hierarchical structure, the AHP has been utilized in multi-criteria decision making. Environmental research, strategy development, product planning, strategic decision making, supply chain management system analysis, and other fields have all used it (Hadipour \& Kishani, 2014). The most difficult part of performing a land suitability study for a specific land use type is determining the relative weights of the entity criteria to be evaluated. As a result, the parameters for the study were narrowed to the nine most relevant features.

AHP can be performed by following some specific steps. First of all creating a hierarchy decision to break the problem into a series of linked decision pieces. Secondly, comparing decision elements and finally, calculate and combine the relative weights of decision aspects.

The consistency of the derived criteria weights should be considered in the second phase. In pairwise comparisons, decision makers are rarely consistent in their estimation of these weights (Zahedi, 1986; UN, 2009). The envisioned pairwise comparison matrix's Consistency Index CI is defined as (equation 12)-

$$
C I=\frac{\lambda \max -}{n-1}
$$

Where, $\lambda_{\max }=$ Average value of the consistency vector, $\mathrm{n}=$ Number of criteria

When the comparison matrix is generated without any consensus amongst decision makers on criteria weights, the Random Index, or RI, serves as a point of reference for consistency. The Consistency Ratio, or CR, assesses how well decision makers agree, for example, how much the pairwise comparison matrix scores were created at random rather than based on an objective, common set of criteria. The consistency ratio is calculated as follows (equation 13):

$$
C R=\frac{C I}{R I}
$$

A value of $\mathrm{CR}<0.1$ gives reasonable consistency. If there is any inconsistency when it comes to the weight of the criterion, the pair-wise comparison should be re-stimulated.

Studies have been carried out to assess the effectiveness of AHP. For example, in Iasi City, (Banica et al. 2017) conducted a multi-criteria analysis of seismic vulnerability (Romania). Physical and social indices, as well as accessibility from/to emergency services/hospitals, are all considered. Standardization (Z score) was used to analyze the indicators, which were then processed, correlated and integrated into an AHP. A (integrated) seismic vulnerability index was calculated by adding the weighted values of the standardized indicators. Using the analytic hierarchy technique, (Alshehri et al. 2015) established a weighting scheme for each dimension and criteria (AHP). Multiple indices, including social, physical, environmental, economic, governance, information, and communication, were used to build the AHP model's hierarchical structure. An AHP-based model for disaster-resilient coastal communities has been created by (Orencio \& Fujii 2013). Several criteria were used in the AHP model to prioritize criteria for a disaster-resilient coastal community including Natural Resource Management, Human Well-Being, Social safety and Protection, Physical Protection Structural and Technical Measures, and Planning Regimes. Environmental and natural resource management, sustainable livelihood regimes were found to be very essential, accounting for greater than or equal to $70 \%$ of the aggregate weights of criteria compared.

\subsubsection{Nardo build composite indicators}

This strategy was developed using a composite indicator approach that was tested in 50 Spanish cities (Nardo et al. 2005). The methodology were adopted according to the steps as follows : (i) determining an appropriate 
scale; (ii) defining key factors for long-term resilience; (iii) identifying specific indicators; (iv) normalizing data; and (v) employing proper weight and aggregating data.

\section{(i) Determining spatial scale of analysis}

As municipalities are the smallest political units with normative competencies and have the smallest spatial scale with centralized statistical data, they were chosen as the spatial scale.

\section{ii) Key factors for long term resilience}

To choose indicators, first identify the important components that affect urban resilience and how they affect the system's resilience as index variables (Bossel, 1999). The method identifies the most essential aspects described in the literature, focusing on those we believe are most important from a social-ecological standpoint for urban contexts. The most important characteristics in creating urban resilience are diversity, modularity, tight feedbacks, social stability, and creativity, according to the findings.

(iii) Selecting indicators

Researchers like Suárez et al. (2016) have only included the following in the urban resilience index due to a lack of accessible data for the 50 Spanish province capitals: company diversity, land use diversity, food source diversification, self-sufficiency, and venues for public involvement (Table 3).

Table 3: Indicators that make up the urban resilience index

\begin{tabular}{|c|c|c|c|c|c|}
\hline Indicator & $\begin{array}{l}\text { Factors that } \\
\text { Measure }\end{array}$ & Calculation & $\begin{array}{l}\text { Effect on } \\
\text { Resilience }\end{array}$ & $\begin{array}{l}\text { Units of } \\
\text { Measure }\end{array}$ & Year \\
\hline Business diversity & $\begin{array}{l}\text { Diversity and } \\
\text { modularity }\end{array}$ & $\begin{array}{l}\text { Index name: Shannon } \\
\text { diversity } \\
\text { Number of categories: } 4\end{array}$ & Positive & Dimensionless & 2007 \\
\hline Land use & Diversity & $\begin{array}{l}\text { Index name: Shannon } \\
\text { diversity } \\
\text { Number of categories: } 9\end{array}$ & Positive & Dimensionless & 2005 \\
\hline Food diversity & Diversity & $\begin{array}{l}\text { Index name: Shannon } \\
\text { diversity } \\
\text { Number of categories: } 37\end{array}$ & Positive & Dimensionless & 2009 \\
\hline
\end{tabular}

(iv) Normalization of data, weighting and aggregation

The final urban resilience indicator is made up of two sub-indices, each of which is measured by one or more indicators (Figure 2).

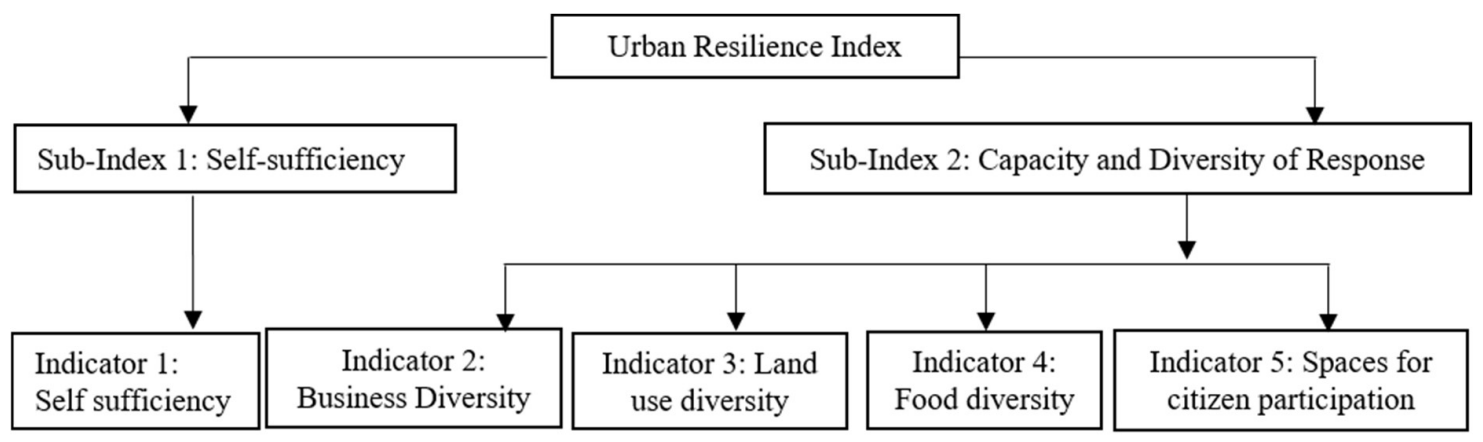

Figure 2: Nardo's build composite indicators frameworks 
To combine these four indicators into a single sub-index, each indicator was rescaled in different literature such as Suárez et al. (2016); Nardo et al. (2005). The scale value for each indicator was calculated using the equation (14) below:

Here $\mathrm{V}=$ Value

$$
\text { Indicator }=\left(\mathrm{V}_{\text {Real }}-\mathrm{V}_{\mathrm{Min}}\right) /\left(\mathrm{V}_{\text {Max }}-\mathrm{V}_{\mathrm{Min}}\right)
$$

As it was unclear which of the factors aggravating the sub-index potential and diversity of response has a stronger impact on resilience, the aggregation convention utilized here was to allocate equal weight to them. The following process (equation 15) is used to compute the index:

$$
\text { Resilience }=\left(\mathrm{H}_{\text {business }}+\mathrm{H}_{\text {landuse }}+\mathrm{H}_{\text {food }}+\mathrm{LA} 21\right) /(\mathrm{EF} / \text { area })
$$

Where "EF" is the ecological footprint of the municipality, "area" is the area measured in hectares, " $\mathrm{H}_{\text {business" }}$, " $\mathrm{H}_{\text {land use }}$ ", " $\mathrm{H}_{\text {food" }}$ " are diversity of business, land use and food accordingly. "LA21" is Local Agenda 21 progress.

According to the findings of Suarez, Gómez-Baggethun, Benayas, \& Tilbury (2016), the majority of Spanish province capitals have low resilience. Cáceres, Cuenca, Albacete, and Badajoz are the most resilient province capitals in Spain according to research findings (Suárez et al. (2016). Córdoba, Teruel, Jaén, and vila have resilience scores of 48, 34, 27 and 23, respectively. The remaining Spanish province capitals have scores of less than $20 \%$, while $60 \%$ of municipalities have ratings of less than $10 \%$.

The observed resilience measures are heavily influenced by population density. Cádiz, Bilbao, and Barcelona, for example, have the highest population density and are therefore the least resilient. Their municipal districts are virtually fully urbanized (Suárez et al. 2016), hence their carrying capacity is greatly exceeded due to the lack of alternate ecosystems. The most robust cities, on the other hand, are those with the greatest municipal areas, which means that population density is low and carrying capacity is less than ten times the municipal size. There are several exceptions, such as Zaragoza, Murcia, and Madrid. That is why, the wide range of carrying capacity surplus, self-sufficiency has been used to determine resilience levels. Because of their low population densities, the most robust province capitals are those that have a lower carrying capacity.

When comparing localities with identical carrying capacity constraints, the remaining indicators become useful. Our findings also demonstrate that, because the value range of Local Agenda 21 development is larger, it has a stronger impact on resilience than the diversity indicators. Food diversity values have a greater degree of unpredictability than business and land use diversity, and so have a greater impact on resilience values. Inland cities in southern rural Spain have the highest levels of resilience (Suárez et al. 2016), whereas all coastal municipalities have low levels of resilience. Other socio-demographic parameters that could explain resilience outcomes have yet to be discovered.

\subsubsection{Hyogo framework}

Disaster risk reduction is a multifaceted strategy. Preparation, execution, and evaluation of DRR (disaster risk reduction) entail broad concepts and systems that aren't limited to specific types or times of action. The Hyogo Framework for Action 2005-2015, adopted in January 2005 at the Second World Conference on Disaster Reduction in Kobe, Japan, was the most significant of these to date (Bradshaw 2013). The Hyogo framework was created to reduce catastrophe risk and provide communities with a stable socioeconomic situation. By using the Hyogo framework in a given location, it is possible to prioritize DRR while also increasing understanding and awareness of the risks. (Olowu 2010). The Sendai Framework replaces the Hyogo Framework for Action (HFA) from 2005 to 2015. Sendai for Catastrophe Risk Reduction 2015-2030 includes four action goals to prevent new disaster risks and minimize current ones and improving disaster readiness for effective response, as well as "Building Back Better" in recovery, rehabilitation, and reconstruction (Nations 2015).

There are many different sorts of disaster risk reduction techniques and tactics. Depending on the severity of the crisis, response types may alter. Risk-based or climate-adoption-based disaster risk reduction strategies are both viable options (Adnan 2014). Response, recovery, and rehabilitation are traditional catastrophe risk reduction strategies (Klein et al. 2003). Reforestation and other landscaping, trash management, environmentally 
sustainable farming and weeding methods, terracing, and creating protective stone and fortifications to prevent rapid run-off of water are all examples of ways to control and recharge natural resources (Bradshaw 2013). New Orleans is a good example of a city that has adopted a response-based strategy (Hanson, et al. 2010). A response-based strategy considers a hazard's past experience in order to demonstrate future investment in order to prevent the occurrence of similar hazards in the future. By examining the types of adjustments that should be performed, changing the land use pattern may be useful in avoiding hazardous effects (Klein et al. 2003). Sustainable planning mechanisms and locational appropriateness analyses can play an important role in city planning, development, and short/long term disaster risk reduction for guaranteeing safe city identification of disaster-prone locations and land use planning (UNISDR, 20005). DRR plans are linked to local hazards, risks, vulnerabilities, and capacities, resulting in government-planned actions.

Planning, regulations, and preventive initiatives can help to prevent and reduce losses before, during, and after a crisis. Risk reduction and early disaster recovery are intertwined with the concept of a safe city. The concept of a safe city encompasses a variety of perspectives, including the role of decision-making, urban planning practice, disaster sociology, and the application of sustainable policies and principles (Smith and Wenger 2007). Growth management, zoning laws, construction codes, and specific hazard resilient buildings are all examples of planning policies, rules, and processes that can make a significant impact (J.Rasigha 2016). However, structural measures have been criticized because cities in wealthier countries may take unique structural measures, whereas developing and poor countries cannot provide structural growth due to a lack of investments (Hanson, et al. 2010). Apart from that, relocating is a lengthy and complicated process that necessitates remuneration. Another crucial truth is that certain tactics may limit the structural protection system's exposure, which would otherwise result in considerable damage (Harvey and Nicholls 2008).

\section{SOME OTHER APPROACHES}

Assessing the disaster resilience of urban communities gives for a better understanding of the disaster's or climate change's impact. Disaster resilience is required to reconstruct a disaster-affected community to predisaster levels in order to improve adaptation. Aside from the ideas or methodologies covered in this review article, some other approaches to catastrophe risk reduction and city resilience have been implemented. For example, the International Federation of Red Cross and Red Crescent Societies (IFRC) has produced an IFRC framework (Societies, 2014). The IFRC framework's purpose is to construct, develop, and sustain a foundation on which all IFRC programmes, projects, interventions, and actions that contribute to the strengthening of resilient communities can be formed, developed, and supported across contexts.

In 2014, UNDP defined resilience as an inherent and acquired condition achieved by managing risks over time at the individual, household, community, and societal levels in ways that reduce costs, build capability to control and sustain development momentum, and maximize transformative potential. The United Nations Development Programme (UNDP, 2014) created a framework called (CoBRA). Components of potential indicators were first chosen based on physical, human, financial, natural, and human categories in the CoBRA framework, and then a resiliency assessment was conducted in the areas of Hazards and Stresses Disaster Preparedness, Future Uncertainty and Adaptive Capacity, Livelihoods Diversity and Security, and Governance Enabling Environment.

The CARRI framework was discussed by (White, Edwards, Farrar, \& Plodinec, 2015). The goal of CARRI's research was to look at the recovery/resilience portion of the "loss-recovery curve" in real-world community resilience practices, as well as to identify and give tools to help enhance community resilience. CARRI chose a "practice" based approach that could bring immediate benefit to the nation's cities and locales. CARRI began by hosting broad, exploratory dialogues with leaders from a wide range of organizations working in and supportive of community resilience across the country, including Federal agencies, private sectors, state and local civic.

ResiliUS (US, Resilience Institute is part of Western Washington University's Huxley College of the Environment) is another methodology established by (Miles \& Chang, 2011). Socioeconomic actors (households and companies) are positioned within specific neighborhoods, which are contained inside a larger community, according to ResilUS' conceptual model. The harm associated with a hazard occurrence to three parts of community capital: the physical built environment, economics, and personal capital is formally 
represented by ResilUS (i.e., health). The ability to perform and the opportunity to perform are two generic indications of recovery used by ResilUS. Multiple variables in ResilUS are used to indicate these recovery signs. ResilUS is implemented and executed in the MATLAB/Simulink modeling package. Markov chains are used to implement ResilUS' recovery dynamics. Each model state is calculated for a certain dynamic (timebased) output by comparing a uniform random number to the sum of all input variables presented as probabilities (e.g., the probability of restored water service in a neighborhood). ResilUS is modular, which means that the way of implementing a specific model can be modified without compromising the entire model's functionality. In addition, the modularity makes it easier to replace a model reference with a data source. Finally, ResilUS can handle an unlimited number of neighborhoods and agents.

\section{DISCUSSION}

Urban resilience to climate change is a complex issue, but measurable. By careful selection and scientific tests, urban resilience to climate change can measured by different approaches of urban resilience indexing ( Adnan, 2014; Ahmed et al. 2004; Banica et al. 2017).

The BRIC index employs a capital-based methodology to provide an overall baseline assessment for assessing existing qualities of natural disaster resilience. BRIC, which was created for US counties, can be used to compare one county to another, to better understand the specific causes of resilience in different counties, and to tracks gradual improvements. The CDRI attempted to extract specific characteristics of risk drivers, such as ecosystem quality, unplanned urbanization, industrialization, or urban poverty, and measures them using a variety of factors (parameters and variables) represented in multiple dimensions (such as poverty). Simpson's community resilience index shows that community that has the highest weight among the preparedness dimensions, and current conditions while the level of activity to improve the community competence subdimension is high, the community's understanding of disaster risk and mitigation is still low. The AHP technique, in particular, guarantees that city planners and decision-makers have access to integrated information on urban climate change resistance. It allows for a systematic comparison of cities, which aids in the quantitative determination of success or failure, as well as the identification of priorities. It also allows for the exploration of relationships between the total AHP and specific components of urban climate change resilience. The AHP allows for the measurement of not just general indicators of urban climate change resilience, but also individual components of urban resilience and their associated indicators. As a result, it may be able to address a wide range of policy and research requirements. The Hyogo Framework for Action is a global catastrophe risk reduction strategy that aims to significantly reduce catastrophic losses in human lives and socioeconomic assets. Ensure that disaster risk reduction is a national and local priority, with a strong institutional foundation for execution, according to the Hyogo Framework for Action (HFA). It also uses innovation and education to promote a culture of safety and resilience at all levels, identifying, assessing, and monitoring disaster risks and improving early warning. Aside from reducing underlying risk factors, the Hyogo framework strengthens disaster preparedness for efficient response at all levels.

Resilience was first mentioned in the context of numerous concepts. We did analysis based on social, economic, infrastructural, environmental, and institutional indicators, which can be considered as qualitative analysis in CDRI framework. Similarly, BRIC, AHP, Hyogo as well as Nardo's Build Composite Indicators methods are considered as quantitative analysis. Resilience has been altered and accepted by a variety of academic sectors. Because of this, the current study incorporates all of the many perspectives of understanding, including the ones related to regime change, the equilibrium and recovery, and the ecology.

\section{CONCLUSION}

The paper discussed about adaptation of urban resiliency method by several countries and cities around the world. Each resiliency method was adopted based on the socio, economic and environmental characteristics of that particular country. The analysis shows different results for different methods applied in different countries. In case of BRIC method higher scores mean higher resiliency and lower score indicates lower resiliency. Similar 
analytical interpretation is seen in case of CDRI framework. In case of Simpsons Community Resilience Index applied in Indonesia the end result shows when urban resiliency score is more than 1 the region is considered to be resilient and when the resiliency score is less than 1 the country is at risk. Nardo Build Composite Indicators shows that inland cities in southern rural Spain have the highest levels of resilience than coastal regions. On the one hand, these methods provide a baseline by which the selected cities or countries resiliency can be measured in the future to discover increases or declines in resilience. Besides, they proposes a methodological approach to measuring urban resilience that can be used as a foundation for future research to improve it, taking into account the methodological implications and data limitations described in this study. As a result, the methodologies have been thoroughly described so that it can be replicated, used, and modified in accordance with the user's specific interests. This review proposes that the climate is changing, theory of social-ecological resilience is improving day by day and urban resilience index should be changed as well. It also suggests that experts and people who might use the index be involved in the development process to make it more relevant and realistically attainable.

\section{REFERENCES}

Adnan, M. S. G., New Framework for Developing Disaster Risk Reduction Plans for Delta Cities - An Application on Chittagong City, Bangladesh (2014). (Master of Science). UniversitatInternacional de Catalunya, Barcelona, Spain; July 2014. doi:10.13140/RG.2.2.31566.69442/1. Available at SSRN: http://dx.doi.org/10.2139/ssrn.3668579.

Ahmed, R., Seedat, M., Niekerk, A. v., and Bulbulia, S., 2004. Discerning community resilience in disadvantaged communities in the context of violence and injury prevention. South African Journal of Psychology, https://doi.org/10.1177/008124630403400304, 34(3), 386-408.

Alshehri, S. A., Rezgui, Y., and Li, H., 2015. Disaster community resilience assessment method: a consensusbased Delphi and AHP approach. Natural Hazards. doi: 10.1007/s11069-015-1719-5

Alwang, J., Siegel, P. B., and Jorgensen, S. L., 2001. Vulnerability: a view from different disciplines (English). Washington, D.C. http://documents.worldbank.org/curated/en/636921468765021121/Vulnerability-aview-from-different-disciplines: Social Protection discussion paper series World Bank Group.

Banica , A., Rosu , L., Muntele , I., and Grozavu , A., 2017. Towards Urban Resilience: A multi-criteria analysis of seismic vulnerability in iasi city (Romania). doi:10.3390/su9020270

Bossel, H., 1999. Indicators for Sustainable Development: Theory, Method, Applications . Winnipeg, MB, Canada: International Institute For Sustainable Development.

Boutkhoum, O., Hanine, M., Agouti, T., and Tikniouine, A., 2014. An improved hybrid multi-criteria/ multidimensional model for strategic industrial location selection: Casablanca industrial zones as a case study. Springerplus, 628.

Bradshaw, S., 2013. Disaster Risk Reduction. In J. Twigg, Disaster Risk Reduction (pp. 156-177). Edward Elgar Publishing.

CMDA, 2008. Second master plan for Chennai metropolitan area, 2026, volume I vision, strategies and action plans . Chennai: Chennai Metropolitan Development Authority.

Cutter, S. L., Burton, C. G., and Emrich, C. T., 2010. Disaster Resilience Indicators for Benchmarking Baseline Conditions. Journal of Homeland Security and Emergency Management, 7(1), 1-25. doi: 10.2202/1547-7355.1732.

Cutter, S. L., Ash, K. D., and Emrich, C. T., 2014. The geographies of community disaster resilience. Global Environmental Change, 65-77. http://dx.doi.org/10.1016/j.gloenvcha.2014.08.005.

Folke, C., 2006. Resilience: The emergence of a perspective for social-ecological systems analyses. Global Environmental Change, 16(3), 253-267. https://doi.org/10.1016/j.gloenvcha.2006.04.002.

Godschalk, D. R., 2003. Urban hazard mitigation: creating resilient cities. Natural Hazards Review, https://doi.org/10.1061/(ASCE)1527-6988(2003).

Gregg, C. E., Houghton, B. F., Paton, D., Lachman, R., Lachman, J., Johnson, D. M., and Wongbusarakum, S., 2006. Natural warning signs of tsunamis: human sensory experience and response to the 2004 great Sumatra earthquake and tsunami in Thailand. Earthquake Spectra, 22(3), 671-691. https://doi.org/10.1193/1.2206791.

Hadipour, M., and Kishani, M., 2014. Environmental location planning of industrial zones using AHP and GIS in Arak city, Iran. GlobalIlluminators, 109-114.10.22034/JEST.2018.10727.1930.

Hanson, S., Nicholls, R., Ranger, N., Hallegatte, S., Morlot, J. C., Herweijer , C., and Chateau, J., 2010. A global ranking of port cities with high exposure to climate extremes. Climatic Change , 114 (1), 89111. Doi:10.1007/s10584-010-9977-4 
Harvey, N., and Nicholls, R., 2008. Global sea-level rise and coastal vulnerability. Integrated Research System for Sustainability Science and Springer, 3(1), 5-7. DOI:10.1007/s11625-008-0049-x doi:10.1007/s11625-008-0049-x, 5-7.

J.Rasigha, C. N., 2016. Design of structures to resist multi hazards. International Journal of Innovative Research in Science, Engineering and Technology.

Jabareen, Y., 2013. Planning the resilient city: concepts and strategies for coping with climate change and environmental risks. , 31(1), 220-229.https://doi.org/10.1016/j.cities.2012.05.004

Joerin, J., Shaw, R., Takeuchi, Y., and Krishnamurthy, R. (2014). The adoption of a Climate Disaster Resilience Index in Chennai, India. Disasters, 38(3), 540-561. doi:10.1111/disa.12058.

Klein, R. J., Nicholls, R. J., and Thomalla, F., 2003. Resilience to natural hazards: how useful is this concept? Environmental Hazards, 5(2), 35-45. doi:10.1016/j.hazards.2004.02.001.

Klein, R. J., Nicholls, R. J., and Thomalla, F., 2004. Resilience to natural hazards: How useful is this concept? Environmental Hazards, doi: 10.1016/j.hazards.2004.02.001, 5(1-2), 35-45.

Kusumastuti, R. D., Viverita, Husodo, Z. A., Suardi, L., and Danarsari, D. N., 2014. Developing a resilience index towards natural disasters in Indonesia. International Journal of Disaster Risk Reduction, $327-$ 340. https://doi.org/10.1016/j.ijdrr.2014.10.007.

Leichenko, R. (2011). Climate Change and Urban Resilience:. Current Opinion in Environmental Sustainability 3(3):164, 164-168. Doi: 10.1016/j.cosust.2010.12.014

Miles, S. B., and Chang, S. E., 2011. ResilUS: a community based disaster resilience model. Cartography and Geographic Information Science, 38(1), 1-18.

Nardo, M., Saisana, M., Saltelli, A., Tarantola, S., Hoffman, A., and Giovannini, E., 2005. Handbook on Constructing Composite Indicators: Methodology and User Guide. France: OECD Statistics Working Papers. OECD Publishing. http://dx.doi.org/10.1787/533411815016.

Nelson, D. R., Adger, W. N., and Brown, K., 2007. Adaptation to environmental change: contributions of a resilient framework. The Annual Review of Environment and Resources, 32(1), 395-419.doi: 10.1146/annurev.energy.32.051807.090348

OECD, 2010. Cities and Climate Change. Paris: OECD Publishing.https://www.oecd.org/env/cities-andclimate-change-9789264091375-en.htm

Olowu, D., 2010. The Hyogo Framework for Action and its implications for disaster management and reduction in Africa. Disaster Risk Studies, 303-320.

Orencio, P. M., and Fujii, M., 2013. A localized disaster-resilience index to assess coastal communities based on an analytic hierarchy process (AHP). International Journal of Disaster Risk Reduction, 3, 62-75. http://dx.doi.org/10.1016/j.ijdrr.2012.11.006.

Rickson, P., 2020. Resilience definition: what is it, meaning, examples and areas of use. Retrieved from Youmatter.world: https://youmatter.world/en/definition/definitions-resilience-definition-meaningexamples.

Robinson, P., \& Gore, C. (2015). Municipal Climate Reporting: gaps in monitoring and implications for governance and action. Environment and Planning C: Government and Policy, 33(5), 1058-1075.

Scherzer, S., Lujala, P., and Rød, J. K., 2019. A community resilience index for Norway: An adaptation of the Baseline Resilience Indicators for Communities (BRIC). International Journal of Disaster Risk Reduction, 101-107. doi: https://doi.org/10.1016/j.ijdrr.2019.101107.

Simpson, D. M., 2006. Indicator issues and proposed framework for a Disaster Preparedness Index (DPI). Louisville: Center for Hazards Research and Policy Development, University of Louisville.

Smith , G. P., and Wenger, D., 2007. Sustainable disaster recovery: operationalizing an existing agenda. Sustainable Disaster Recovery, 234-257.

Societies, I. F., 2014. IFRC Framework for Community Resilience. Geneva.https://www.ifrc.org/document/ifrcframework-community-resilience

Suárez, M., Gómez-Baggethun, E., Benayas, J., and Tilbury, D., 2016. Towards an urban resilience index: a case study in 50 Spanish cities. Sustainability, 8(4), 1-19. doi:10.3390/su8080774.

Tylor, S., and Monech, M., 2012. A framework for urban climate resilience. Climate and Development, 4(4), 311-326. doi: 10.1080/17565529.2012.745389

UN, 2015. Sendai framework for Disaster Risk Reduction 2015-2030. Sendai.https://www.undrr.org/publication/sendai-framework-disaster-risk-reduction-2015-2030

UN, 2009. Terminology on Disaster Risk Reduction. Geneva: United Nations International Strategy for Disaster Reduction (UNISDR).

UNDP, 2014. Community Based Resilience Analysis (CoBRA) Conceptual Framework and Methodology.

UNISDR, 20005. Hyogo Framework for Action: 2005-2015, Building the Resilience of Nations and Communities to Disasters.

UNISDR, 2015. UNISDR annual report. Sendai, Japan : United Nations Office for Disaster Risk Reduction. 
Walker, B., Anderies, J. M., Kinnzig, A. P., and Ryan, P., 2006. Exploring resilience in social-ecological systems through comparative studies and theory development: introduction to the special issue. Ecology and Society, 11(1), 1-12. doi: 10.5751/ES-01573-110112.

White RK, Edwards WC, Farrar A, Plodinec MJ. A practical approach to building resilience in America's communities. American Behavioral Scientist. 2015;59(2):200-219. doi:10.1177/0002764214550296

Zahedi, F., 1986. The Analytic Hierarchy Process-a survey of the method and its applications. Institute for Operations Research and the Management Sciences, 96-108, 16(4). https://doi.org/10.1287/inte.16.4.96

(C) 2021 the JES. Journal of Engineering Science published by Faculty of Civil Engineering, Khulna University of Engineering \& Technology. This is an open access article under the terms of the Creative Commons AttributionNonCommercial-NoDerivatives License, which permits use and distribution in any medium, provided the original work is properly cited, the use is non-commercial and no Modifications or adaptations are made. 